\title{
Anabases
}

ANABASES Traditions et réceptions de l'Antiquité

$14 \mid 2011$

Varia

\section{Pietro CONTE, Mito e tradizione: Johann Jakob Bachofen tra estetica e filosofia della storia}

\section{Sarah Rey}

\section{OpenEdition}

\section{Journals}

Édition électronique

URL : http://journals.openedition.org/anabases/2845

DOI : $10.4000 /$ anabases. 2845

ISSN : 2256-9421

\section{Éditeur}

E.R.A.S.M.E.

\section{Édition imprimée}

Date de publication : 1 octobre 2011

Pagination : 291-292

ISSN : 1774-4296

\section{Référence électronique}

Sarah Rey, "Pietro conte, Mito e tradizione : Johann Jakob Bachofen tra estetica e filosofia della storia », Anabases [En ligne], 14 | 2011, mis en ligne le 01 octobre 2011, consulté le 22 septembre 2020. URL: http://journals.openedition.org/anabases/2845 ; DOI : https://doi.org/10.4000/anabases.2845

Ce document a été généré automatiquement le 22 septembre 2020.

(c) Anabases 


\title{
Pietro CONTE, Mito e tradizione : Johann Jakob Bachofen tra estetica e filosofia della storia
}

\author{
Sarah Rey
}

\section{RÉFÉRENCE}

Pietro CONTE, Mito e tradizione : Johann Jakob Bachofen tra estetica e filosofia della storia, Milan, Il Filarete, Pubblicazioni della Facoltà di Lettere e Filosofia dell'Università degli studi di Milano, 2009, $170 \mathrm{p}$.

22 euros / ISBN 9788879164412.

Cette étude, issue d'une thèse de doctorat, est consacrée aux aspects théoriques de l'œuvre de J.J. Bachofen (1815-1887). Pietro Conte, philosophe de formation, a voulu situer la pensée de l'auteur de Mutterrecht (1861) et Die Sage von Tanaquil (1870) dans une longue généalogie: de Herder et Humboldt en amont à Burckhardt, Nietzsche, Warburg, Benjamin et Thomas Mann en aval, pour mettre à mal sa "mauvaise réputation » de philologue sorti du droit chemin de l'érudition. L'autobiographie et la correspondance du savant de Bâle ont nourri cette analyse d'histoire des idées. Le livre est ordonné en deux parties («Storia» et «Estetica») et six chapitres aux titres élégants mais un peu allusifs: "Il delitto", «Hypotheses non fingo", "Mito è monumento : la tradizione (di ciò che non è mai accaduto)", « Tombe ", « Parlare per immagini », " "Verso una nuova quinta di sabbia". Da Bachofen a Thomas Mann». L'itinéraire de Bachofen est brièvement retracé, depuis sa formation aux côtés des grands maitres (Boeckh, Ranke, Savigny) jusqu'à son changement de cap scientifique : un beau jour, les études microscopiques de droit antique et médiéval auxquelles il se vouait ne lui ont plus suffi, il s'est engagé alors sur les voies «de traverse » de la mythologie. On l'aperçoit en contempteur du temps présent, admirateur d'une 
Antiquité plus intrinsèquement religieuse que les siècles modernes, défenseur d'un passéisme dynamique.

2 Le lecteur historien pourra peut-être regretter l'absence de «chair » de cet ouvrage : on aurait aimé en savoir plus sur le voyage de Bachofen en Étrurie, choc esthétique qui décide de sa nouvelle orientation "mythographique ». Un siècle avant que n'explose le gender, l'importance des figures féminines dans les travaux du Bâlois n'est pas non plus l'objet de considérations spéciales. Et rien n'est dit des enjeux nationaux attachés au développement des «sciences de l'Antiquité »; pourtant, la Suisse alémanique, berceau de cet Altertumswissenschaftler, n'est pas exactement l'Allemagne. Pour une approche moins philosophique mais plus historiographique et anthropologique de Bachofen, on pourra consulter La mythologie du matriarcat (1999), ouvrage collectif dirigé par Philippe Borgeaud et, paru récemment, $L a$ déesse et le grain. Trois essais sur les religions néolithiques (2010) d'Alain Testart.

3 Malgré tout, ce livre permet de retrouver les contradictions d'un homme qui, comme Michelet, aimait la mort et la «chaleur» des tombeaux (p. 28) et qui proclamait tout fort son positivisme en voulant devenir le plus romain possible (lettre de J. J. Bachofen à W. Henzen, 6 octobre 1850).

\section{AUTEURS}

\section{SARAH REY}

Université de Paris Est/Marne-la-Vallée

sarah-rey@hotmail.fr 